\title{
Long-term results and management of ureteral transitional cell carcinoma using the holmium: YAG laser via rigid-ureteroscopy
}

\author{
YOSHIAKI YAMADA ${ }^{1}$, YASUSUKE INOUE ${ }^{2}$, KOGENTA NAKAMURA $^{1}$, KATSUYA NARUSE $^{1}$, \\ SHIGEYUKI AOKI ${ }^{1}$, TOMOHIRO TAKI ${ }^{1}$, MOTOI TOBIUME ${ }^{1}$, KENJI ZENNAMI ${ }^{1}$, REMI KATSUDA ${ }^{1}$, \\ KOUJI HARA ${ }^{1}$, YOSHIHARU KATO ${ }^{1}$, MASAHITO WATANABE ${ }^{1}$, KEIKO HAYASHIDA ${ }^{3}$, YUMI SUZUKI ${ }^{3}$, \\ HITOMI KATO $^{3}$, REIKO AJISAKA ${ }^{3}$, INBOU KYOKU ${ }^{4}$, HIROSHI NOGUCHI ${ }^{2}$ and NOBUAKI HONDA ${ }^{1}$ \\ ${ }^{1}$ Department of Urology, ${ }^{2}$ Department of Emergency and Critical Care Medicine, Aichi Medical University \\ School of Medicine; ${ }^{3}$ Division of Nursing, Aichi Medical University Hospital, Nagakute, Aichi; \\ ${ }^{4}$ Department of Urology, Kainan Municipal Hospital, Kainan, Wakayama, Japan
}

Received June 30, 2008; Accepted September 1, 2008

DOI: $10.3892 /$ or_00000228

\begin{abstract}
The standard operative procedure for ureteral transitional cell carcinoma is nephrouterectomy with partial cystectomy at the affected ureteral orifice. However, nephronsparing surgery and endoscopic surgery and management have become common practice for low-grade and low-stage cases. We investigated the follow-up results of patients who underwent endoscopic surgery using the holmium:YAG laser, and evaluated its treatment effect. The patients were 4 men and 3 women aged from 68 to 87 years (mean: 74.7 years). Two were imperative cases and 5 were elective cases. The tumor size ranged from 8 to $25 \mathrm{~mm}$ (mean: $15.4 \mathrm{~mm}$ ). Hydronephrosis was not found in any case, and urinary cytology was negative in all cases. Biopsy revealed 5 cases of grade 1 , and 2 of grade 2. A Versa Pulse Select 80 laser generator, a $365-\mu \mathrm{m}$ slim line laser fiber, and a rigid ureteroscope with $8 \mathrm{~F}$-point diameter were used. A $6 \mathrm{~F}$ double $\mathrm{J}$ catheter was placed postoperatively for 3 weeks. Pulse energy was set at 0.5-1.0 J (mean: $0.8 \mathrm{~J}$ ) with a frequency of $10 \mathrm{~Hz}$. The total amount of energy was 0.9-11.22 KJ (mean: $2.89 \mathrm{KJ}$ ) and the operation time including ureteral stent placement was 20-97 min (mean: $66 \mathrm{~min}$ ). Neither urinary tract perforation nor ureteral stricture associated with laser irradiation was observed. The postoperative follow-up period ranged from 23-88 months (mean: 67.8 months). Patients underwent urinary cytological examination once a month, and cystoscopy, retrograde pyelography and urethroscopy once every 3 months for 2 years, then once every 6 months thereafter. One patient
\end{abstract}

Correspondence to: Dr Yoshiaki Yamada, Department of Urology, Aichi Medical University School of Medicine, Nagakute, Aichi, 480-1195, Japan

E-mail: yy1124@aichi-med-u.ac.jp

Key words: upper urinary tract, ureteral transitional cell carcinoma, endoscopic surgery and management, holmium:YAG laser, longterm results developed tumor recurrence 23 months after surgery and received another laser treatment, but no recurrence has been observed in the other 6 patients $(85.7 \%)$. Transurethral endoscopic surgery and management using the holmium:YAG laser is safe and effective nephron-sparing surgery for ureteral transitional cell carcinoma, and good long-term treatment results can be expected even in elective cases if the indications are carefully selected.

\section{Introduction}

The development of both flexible and rigid ureteroscopes has enabled surgeons to easily and less invasively approach all parts of the upper urinary tract by means of the transurethral endoscope $(1,2)$. This has made endoscopic observation of upper urinary tract tumors routine practice, and endoscopic treatment such as for superficial bladder cancer is now possible even in the upper urinary tract. We previously reported the indications and safety of the holmium:YAG laser for endoscopic resection of ureteral transitional cell carcinoma (3). Herein, we report a retrospective examination of the longterm treatment effect in patients who we were able to follow-up for $\sim 5$ years.

\section{Patients and methods}

Patients. We evaluated 7 patients diagnosed with ureteral transitional cell carcinoma and treated with the holmium:YAG laser in the Department of Urology, Aichi Medical University Hospital from November 2000 to October 2003. The last observation date was set at December 2007. The patients were 4 men and 3 women aged 68-87 years (mean: 74.7 years). Four had disease on the left side and 3 on the right side.

Hydronephrosis was not found in any case, and urinary cytology was negative in all cases. Biopsy revealed 5 cases of grade 1 and 2 of grade 2 . One patient had a tumor in the middle of the ureter while 6 had a tumor at the lower end of the ureters. Two had a papillary pedunculated solitary tumor and 5 had papillary pedunculated multiple tumors. There were 2 imperative cases ( 1 solitary kidney case and 1 high-risk 

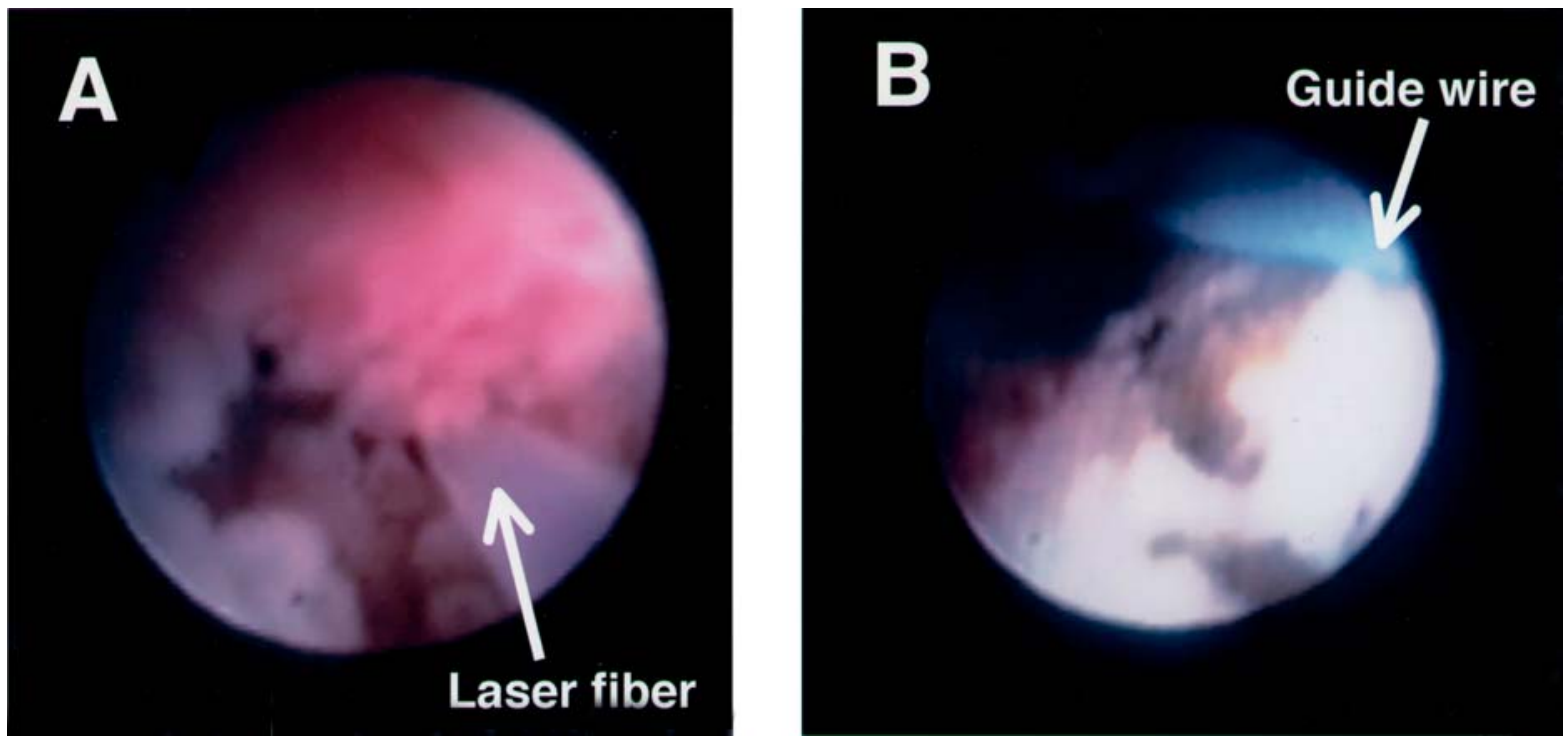

Figure 1. Case 5: Findings of operation. (A) A 365- $\mu \mathrm{m}$ laser fiber was used under direct rigid ureteroscopic visualization to resect a tumor by evaporation of surrounding tissue without touching it. (B) Irradiation stopped after sufficient coagulation of the tumor base and mucosal membrane surrounding it was obtained. No damage to the guide wire was observed.

Table I. Characteristics of seven patients.

\begin{tabular}{|c|c|c|c|c|c|c|c|c|c|c|c|}
\hline Pt. No. & Age & Sex & Side & Site & Biopsy & $\begin{array}{l}\text { Tumor size } \\
(\mathrm{mm})\end{array}$ & Growth pattern & $\begin{array}{c}\text { Preoperative } \\
\text { urine cytology }\end{array}$ & Hydronephrosis & Prior therapy & Past history \\
\hline 1 & 87 & $\mathrm{~F}$ & $\mathrm{Rt}$ & Lower ureter & TCC, G1 & $20 \times 5$ & $\begin{array}{c}\text { Papillary, multiple } \\
\text { pedunculated }\end{array}$ & Negative & None & TUR-Bt & Heart failure \\
\hline 2 & 68 & M & $\mathrm{Lt}$ & Lower ureter & TCC, G1 & $8 \times 4$ & $\begin{array}{c}\text { Papillary, multiple } \\
\text { pedunculated }\end{array}$ & Negative & None & TUR-Bt & $\begin{array}{l}\text { Diabetes } \\
\text { mellitus }\end{array}$ \\
\hline 3 & 80 & M & $\mathrm{Lt}$ & Upper ureter & TCC, G1 & $15 \times 5$ & $\begin{array}{l}\text { Papillary, solitaly } \\
\text { pedunculated }\end{array}$ & Negative & None & $\begin{array}{l}\text { Rt-nephroure- } \\
\text { terectomy }\end{array}$ & None \\
\hline 4 & 71 & M & Rt & Lower ureter & TCC, G2 & $25 \times 3$ & $\begin{array}{c}\text { Papillary, multiple } \\
\text { pedunculated }\end{array}$ & Negative & None & TUR-Bt & Hypertension \\
\hline 5 & 74 & M & $\mathrm{Lt}$ & Lower ureter & TCC, G1 & $20 \times 7$ & $\begin{array}{c}\text { Papillary, multiple } \\
\text { pedunculated }\end{array}$ & Negative & None & TUR-Bt & Enone \\
\hline 6 & 72 & $\mathrm{~F}$ & $\mathrm{Lt}$ & Lower ureter & TCC, G1 & $10 \times 4$ & $\begin{array}{l}\text { Papillary, solitaly } \\
\text { pedunculated }\end{array}$ & Negative & None & TUR-Bt & $\begin{array}{l}\text { Diabetes } \\
\text { mellitus }\end{array}$ \\
\hline 7 & 71 & $\mathrm{~F}$ & $\mathrm{Rt}$ & Lower ureter & TCC, G2 & $10 \times 3$ & $\begin{array}{c}\text { Papillary, multiple } \\
\text { Pedunculated }\end{array}$ & Negative & None & None & None \\
\hline
\end{tabular}

case) and 5 elective cases. The tumor size ranged from 8 to $25 \mathrm{~mm}$ (mean: $15.4 \mathrm{~mm}$ ) (Table I). The World Health Organization classification (4) was used for histopathological grading.

Instruments. A Versa Pulse Select 80 holmium:YAG laser generator, a slim line laser fiber with a core diameter of $365 \mu \mathrm{m}$ and a rigid ureteroscope with $8 \mathrm{~F}$-point diameter were used.

Operation method. Surgery was conducted after each patient was confirmed to have low grade (grade 1 or 2) histology on preoperative biopsy. First, the bladder was confirmed to be tumor-free, and then a 0.035 inch safety-guide wire was placed from the ureteral orifice. Then an 8F-rigid ureteroscope was inserted from the ureteral orifice under direct visualization. Saline was used for perfusion by gravity at a height of $100 \mathrm{~cm}$. Normal ureter above the tumor was confirmed, and a $365-\mu \mathrm{m}$ laser fiber was used carefully, so as not to touch the guide wire, to resect tumor by evaporation of surrounding tissue without touching it. Irradiation was stopped after sufficient coagulation of the tumor base and the mucosal membrane surrounding it was obtained (Fig. 1). A 6F double J catheter was placed for 3 weeks after the operation. 


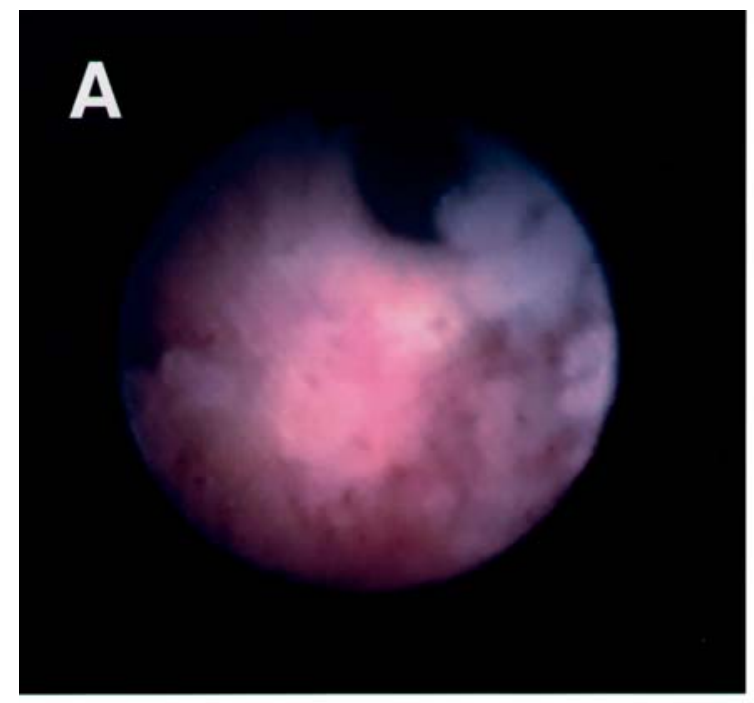

Pre-operation

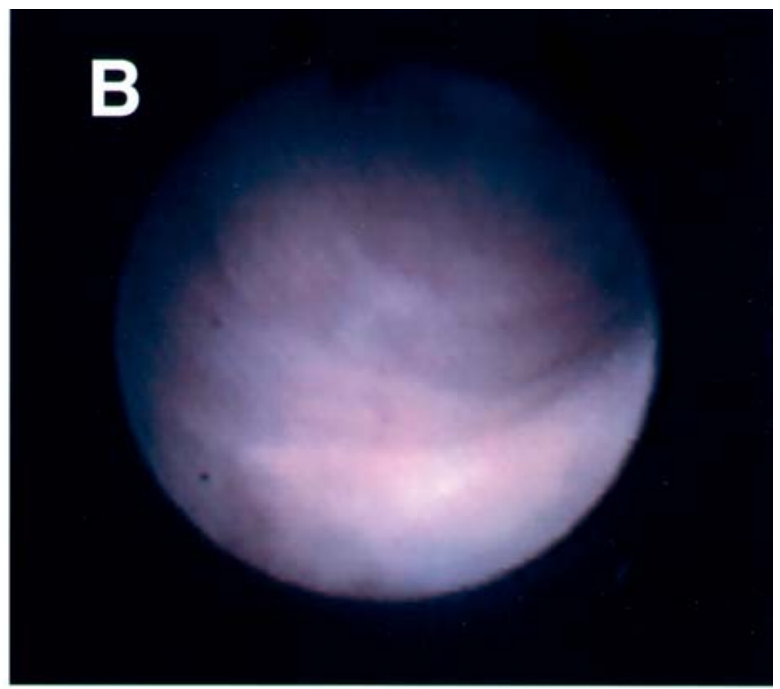

Post-operation (after 24 months)

Figure 2. Case 5: Urereroscopic findings. (A) Initial ureteroscopy revealed multiple pedunculated papillary tumors. (B) Ureteroscopy performed 24 months postoperatively showed no recurrence of cancer.

Table II. Results.

\begin{tabular}{|c|c|c|c|c|c|c|c|}
\hline Pt. No. & Indication & $\begin{array}{l}\text { Energy output, } \\
\text { rate }\end{array}$ & $\begin{array}{c}\text { Total energy } \\
(\mathrm{KJ})\end{array}$ & $\begin{array}{l}\text { Operation time } \\
(\min )\end{array}$ & $\begin{array}{l}\text { Follow-up period } \\
\text { (months) }\end{array}$ & Reccurence & Outcome \\
\hline 1 & Imperative & $0.5 \mathrm{~J}, 10 \mathrm{~Hz}$ & 1.3 & 60 & 23 & Yes & Died of cerebral infarction \\
\hline 2 & Elective & $0.5 \mathrm{~J}, 10 \mathrm{~Hz}$ & 1.02 & 20 & 88 & None & No evidence of disease \\
\hline 3 & Imperative & $1.0 \mathrm{~J}, 10 \mathrm{~Hz}$ & 2.53 & 45 & 84 & None & No evidence of disease \\
\hline 4 & Elective & $0.5 \mathrm{~J}, 10 \mathrm{~Hz}$ & 1.74 & 32 & 78 & None & No evidence of disease \\
\hline 5 & Elective & $1.0 \mathrm{~J}, 10 \mathrm{~Hz}$ & 11.22 & 97 & 78 & None & No evidence of disease \\
\hline 6 & Elective & $1.0 \mathrm{~J}, 10 \mathrm{~Hz}$ & 1.49 & 30 & 67 & None & No evidence of disease \\
\hline 7 & Elective & $1.0 \mathrm{~J}, 10 \mathrm{~Hz}$ & 0.9 & 29 & 56 & None & No evidence of disease \\
\hline
\end{tabular}

\section{Results}

Laser irradiation and operation time. Pulse energy of the holmium:YAG laser was set at 0.5-1.0 J (mean: 0.8 J) and the frequency was $10 \mathrm{~Hz}$. The total amount of energy was 0.9-11.22 KJ (mean: $2.89 \mathrm{KJ}$ ) and the operation time including ureteral stent placement was 20-97 min (mean: $66 \mathrm{~min}$ ).

Postoperative course. No patient received postoperative adjuvant therapy. One patient experienced tumor recurrence 23 months after the operation and underwent another laser treatment. The patient died of cerebral infarction 3 years after the operation. The observation period including this case was 23-88 months (mean: 67.8 months). Patients underwent examination of urinary cytology once a month, and cystoscopy, retrograde pyelography and urethroscopy once every 3 months for 2 years. From then, the patients have been followed every 6 months and no recurrence has been observed in the other 6 patients (85.7\%) (Table II) (Fig. 2).

Complications. No urinary tract perforation associated with laser irradiation occurred. No ureteral stricture has been observed during the follow-up period.

\section{Discussion}

Since upper urinary tract tumors tend to be multifocal, the standard operative procedure is nephrouterectomy with partial cystectomy at the affected ureteral orifice. In addition, since diagnosis and determination of the depth of upper urinary tract tumors are not clear, this procedure has been selected even for small tumors as well as large ones. However, 
recurrence is rare in low-grade and low-stage cancer, and therefore, conservative surgery represented by partial ureterectomy is now commonly performed, especially for small tumors in the lower urinary tract $(5,6)$.

Recently, endoscopy is commonly used to diagnose upper urinary tract tumors, and our group also actively uses endoscopic observation. In our experience, we often encounter cases that could possibly be treated endoscopically such as transurethral resection of bladder cancer.

We have reported the safety and effectiveness of the use of the holmium:YAG laser for endoscopic treatment of ureteral stenosis (7-9). Herein, we used the holmium:YAG laser to resect ureteral cancers and examined 7 patients who we were able to follow-up for a long period of time.

Initially, the tools used for endoscopic resection of upper urinary tract tumors were mainly electric coagulators or ureteroscopes for resection $(10,11)$, but the energy needed for resection was high and they could cause postoperative stricture or perforation due to thermal degeneration of the ureter's thin wall. On the other hand, the laser has a narrow light guide and flexibility, and is suited for both rigid and flexible ureteroscopes with small diameter. Recently, the holmium:YAG laser, which can evaporate, coagulate and resect tumors, has attracted much attention $(5,12)$. The holmium:YAG laser can be used safely since its irradiation affects only the surface. The problem, however, is that postoperative histological diagnosis from resected samples is difficult. In addition, since the holmium:YAG laser is a pulse wave, tumor cells may be scattered in cases of upper tract tumors, and the risk of dissemination cannot be eliminated. However, we are not aware of such a report to date.

Sufficient perfusion is required to smoothly conduct endoscopy. However, if perfusion pressure is increased to secure a sufficient amount of perfusion, the perfusion fluid is absorbed by the vascular system, risking dissemination of tumor cells (13). Therefore, we used saline perfusion by gravity at a height of $100 \mathrm{~cm}$ instead of using a roller pump for perfusion, based on the study that pressure $<75 \mathrm{mmHg}$ does not affect the kidney (14). However, since the pressure was low, we often lost the visual field soon after laser irradiation started and had to stop irradiation to drain the fluid and irradiate again while reinfusing the fluid.

Smith et al (15) considered that the indication for endoscopic treatment is solitary, local, low-grade, non-invasive papillary pedunculated tumor without the complication of other transitional carcinoma, since their recurrence rate is low. Matsuoka et al (16) designated solitary kidney, bilateral disease and high risk cases as imperative cases and low-grade small papillary pedunculated tumors as elective cases. In our study, though some had multiple tumors, all had negative urine cytology and low grade disease at biopsy. However, the most important aspect in deciding to perform endoscopy for upper urinary tract tumors may be the depth of invasion. Imaging such as IVP, RP, CT and MRI are used in urology, but it is difficult to accurately judge the depth with these images. Therefore, the depth of invasion is currently estimated from the diagnosed grade. In addition, since it is difficult to make postoperative histopathological diagnosis with laser ablation, reliable tissue sampling and diagnosis by biopsy are considered crucial. Intraureteral ultrasonography using a $20 \mathrm{MHz}$ small- diameter ultrasound probe has been developed and its effectiveness is currently under review. Small-diameter ultrasonography is expected to play an important role in urological endoscopy in the future (17-19).

Keeley et al (5) reported that they performed nephronsparing surgery for upper urinary tract tumors in 41 kidneys (all had laser ablation) and observed recurrence in 8 (28.5\%) of 28 kidneys that were evaluable. Matsuoka et al (16) reported that $3(16.7 \%)$ of 18 cases (all with holmium:YAG laser ablation) experienced recurrence. The treatment results of 59 upper tract urothelial carcinomas previous studies by Martinez-Pineiro et al (20) revealed the recurrence rate of endoscopic treatment (including electric coagulation and laser ablation) to be $9.5-45 \%$. The mechanism of recurrence has not been elucidated, but multifocal recurrence, where the source of tumor development remains, is believed to be the cause. They also noted that high grade (including grade 3 ) or preoperative urinary cytology-positive cases are more likely to have recurrence. Some reported good treatment results in elective cases $(21,22)$, but we consider the indication for endoscopy treatment is the selection criteria of Matsuoka et al (16) as well as urinary cytology-positive cases.

In all our cases, a ureteral stent catheter was placed for 3 weeks for postoperative management, but catheter placement may not be needed for short-term procedures in the lower ureter. The indication for stent catheter placement should be reconsidered. Furthermore, unlike bladder cancer, there is no established standard therapy to prevent recurrence. Some studies reported that postoperative adjuvant therapy with mitomycin-C or BCG is effective $(5,20,23,24)$, but since they were conducted under various kinds of protocols, the effectiveness is not clear at this point and further research involving more cases is needed.

For postoperative follow-up, Bagley (25) recommended cystoscopy and urinary cytology once every 3 months, urethroscopy once every 6 months and pyelography every 12 months. Chen et al (26) recommended cystoscopy once every 3 months and urethroscopy once every 6 months for 2 years after surgery, and cystoscopy once every 6 months and urethroscopy once a year thereafter. However, considering the detection rate of endoscopy, we think that endoscopic follow-up of the upper urinary tract with cystoscopy is necessary in cases of bladder cancer. Therefore, we observe the renal pelvis and renal calyx with a flexible cystoscope once every 3 months, even though it is an invasive method, in the routine follow-up.

Transurethral endoscopy with the holmium:YAG laser, as nephron-sparing surgery for ureteral transitional cell carcinoma, was safe and effective during a long period of observation. Good long-term results can be expected in elective cases if the indications are carefully selected.

\section{References}

1. Kuo RL, Aslan P, Fitzgerald KB and Preminger GM: Use of ureteroscopy and holmium:YAG laser in patients with bleeding diatheses. Urology 52: 609-613, 1998

2. Ferraro RF, Abraham VE, Cohen TD and Preminger GM: A new generation of semirigid fiberoptic ureteroscopes. J Endourol 13: 35-40, 1999.

3. Yamada Y, Honda N, Nakamura K, et al: Clinical experience of ureteroscopic treatment for urereral transitional cell carcinoma using the Holmium:YAG laser. Oncol Rep 10: 821-825, 2003. 
4. Epstein JI, Amin MB, Reuter VR and Mostofi FK: The World Health Organization/International Society of Urological Pathology consensus classification of urothelial (transitional cell) neoplasms of the urinary bladder. Bladder Consensus Conference Committee. Am J Surg Pathol 22: 1435-1448, 1998.

5. Keeley FX Jr, Bibbo M and Bagley DH: Ureteroscopic treatment and surveillance of upper urinary tract transitional cell carcinoma. J Urol 157: 1560-1565, 1997

6. Pohar KS and Sheinfeld J: When is partial ureterectomy acceptable for transitional-cell carcinoma of the ureter? J Endourol 15: 405-408, 2001.

7. Yamada Y, Honda N, Hibi H, Taki T, Mitsui K and Fukatsu H: Holmium:YAG laser endoureterotomy in the treatment of ureteroenteric stricture following Indiana urinary diversion. Int J Urol 8: 326-329, 2001.

8. Hibi H, Kato K, Mitsui K, Taki T, Yamada Y, Honda N and Fukatsu H: Endoscopic ureteral incision using the holmium: YAG laser. Int J Urol 8: 657-661, 2001.

9. Hibi H, Ohori T, Taki T, Yamada Y and Honda N: Long-term results of endoureterotomy using a holmium laser. Int J Urol 14: 872-874, 2007

10. Huffman JL, Bagley DH, Lyon ES, Morse MJ, Herr HW and Whitmore WF Jr: Endoscopic diagnosis and treatment of upper-tract urothelial tumors. A preliminary report. Cancer 55 $1422-1428,1985$.

11. Blute ML, Segura JW, Patterson DE, Benson RC Jr and Zincke H: Impact of endourology on diagnosis and management of upper urinary tract urothelial cancer. J Urol 141: 1298-1301, 1989.

12. Bagley D and Erhard M: Use of the holmium laser in the upper urinary tract. Tech Urol 1: 25-30, 1995.

13. Lim DJ, Shattuck MC and Cook WA: Pyelovenous lymphatic migration of transitional cell carcinoma following flexible ureterorenoscopy. J Urol 149: 109-111, 1993.

14. Wilson WT and Preminger GM: Intrarenal pressures generated during flexible deflectable ureterorenoscopy. J Endourol 4 135-141, 1990.

15. Smith AD, Orihuela E and Crowley AR: Percutaneous management of renal pelvic tumors: a treatment option in selected cases. J Urol 137: 852-856, 1987.
16. Matsuoka K, Iida S, Kawagoe N, et al: Application of holmium laser treatment for renal pelvic and ureteral carcinoma. Nishinihon J Urol 62: 153-156, 2000 (In Japanese).

17. Grasso M, Liu JB, Goldberg B and Bagley DH: Submucosal calculi: endoscopic and intraluminal sonographic diagnosis and treatment options. J Urol 153: 1384-1389, 1995

18. Liu JB, Bagley DH, Conlin MJ, Merton DA, Alexander AA and Goldberg BB: Endoluminal sonographic evaluation of ureteral and renal pelvic neoplasms. J Ultrasound Med 16: 515-521, 1997.

19. Nakashima M, Yokomizo A, Koga H, Tokuda N, Tanaka M and Naito S: Technique and application of endoluminal ultrasonography using a flexible cystoscope. Nishinihon J Urol 62: 161-166, 2000 (In Japanese).

20. Martinez-Pineiro JA, Garcia Matres MJ and Martinez-Pineiro L: Endourological treatment of upper tract urothelial carcinoma: analysis of a series of 59 tumors. J Urol 156: 389-390, 1996.

21. Chen GL and Bagley DH: Ureteroscopic management of upper tract transitional cell carcinoma in patients with normal contralateral kidneys. J Urol 164: 1173-1176, 2000.

22. Elliott DS, Segura JW, Lightner D, Patterson DE and Blute ML: Is nephroureterectomy necessary in all cases of upper tract transitional cell carcinoma? Long-term results of conservative endourologic management of upper tract transitional cell carcinoma in individuals with a normal contralateral kidney. Urology 58: 174-178, 2001.

23. Eastham JA and Huffman JL: Technique of mitomycin C instillation in the treatment of upper urinary tract urothelial tumors. J Urol 150: 324-325, 1993.

24. Patel A and Fuchs GJ: New techniques for the administration of topical adjuvant therapy after endoscopic ablation of upper urinary tract transitional cell carcinoma. J Urol 159: 71-75, 1998.

25. Bagley DH: Treatment of upper urinary tract neoplasma. In: Smith's Textbook of Endourology. Smith AD, et al (eds). Quality Medical Publishing, St. Louis, MO, pp474-487, 1996.

26. Chen GL and Bagley DH: Ureteroscopic surgery for upper tract transitional-cell carcinoma: complications and management. J Endourol 15: 399-404, 2001. 